\title{
Mechanical failure of total hip arthroplasties and associated risk factors
}

\author{
Henrik C. Bäcker ${ }^{1}\left[\right.$ (D) Chia H. Wu ${ }^{2} \cdot$ Arne Kienzle $^{1} \cdot$ Carsten Perka ${ }^{1} \cdot$ Clemens Gwinner $^{1}$
}

Received: 30 June 2021 / Accepted: 6 January 2022 / Published online: 28 January 2022

(c) The Author(s) 2022

\begin{abstract}
Introduction Mechanical failure of total hip arthroplasties is a rare but devastating complication. With increasing numbers in primary arthroplasty implantation, revision surgeries are indicated more often. Therefore, understanding the mechanism and the location of failure is essential in determining proper treatment. Aim of this study was to identify mechanical failures of all total hip arthroplasties performed in a major academic center as well as the associated risk factors such as BMI and sports. Methods A retrospective trial was conducted using our prospective arthroplasty database. Database was searched for all patients presenting with mechanical failures of total hip arthroplasty (THA) to the emergency department between 2011 and 2019. All medical charts and radiographs as well as surgical reports were analyzed to identify demographics, implant choice in addition to location of failure and subsequent treatment.

Results In total, 13 patients suffering from mechanical total hip implant failure were found. The femoral neck (conus) was broken in four patients, the stem in five cases, one broken inlay, two cup failures and one conus dislocation. The mean BMI was $31.42 \pm 5.29 \mathrm{~kg} / \mathrm{m}^{2}$ including five patients who have obesity class II. In all cases, revision surgeries were indicated. No structural causes or underlying risk factors such as repeated physical load (i.e. in sports) were identified.

Conclusion Implant failure does not seem to correlate with participation in sports or BMI. Catastrophic failure of implants is a technical challenge requiring special extraction instruments that can be difficult even for experienced surgeons. It should be noted that functional outcome is often worse for this group of patients after surgery than comparing against those revised for loosening.
\end{abstract}

Level of evidence. III, Retrospective Trial.

Keywords Arthroplasty $\cdot$ Hip $\cdot$ THA $\cdot$ Failure $\cdot$ Complication $\cdot$ Outcome

\section{Introduction}

Henrik C. Bäcker

henrik.baecker@sports-med.org

Chia H. Wu

wu.chia.h@gmail.com

Arne Kienzle

arne.kienzle@charite.de

Carsten Perka

carsten.perka@charite.de

Clemens Gwinner

clemens.gwinner@charite.de

1 Department of Orthopaedic Surgery and Traumatology, Charité Berlin, University Hospital Berlin, Chariteplatz 1, 10117 Berlin, Germany

2 Department of Orthopedics and Sports Medicine, Baylor College of Medicine Medical Center, Houston, TX, USA
In increase in number of total hip arthroplasties has led to more revision arthroplasties. In the initial years, structural implant failures were described more commonly. However, improvements in surgical techniques and implant quality have led to a decrease in these complications. [1,2] furthermore, U.S. Food \& Drug Administration (FDA) approval is monitoring these events closely in order to minimize adverse events.

Biomechanical studies showed that critical stress within the thin titanium dioxide $\left(\mathrm{TiO}_{2}\right)$ can lead to micro cracks that subsequently become structural failure [3]. In addition, corrosive environment such as oxidative stress may predispose implant to failure. [4] As such, modular prosthesis is thought to be at higher risk for failure especially at the taper junction. [5] These have shown increased fretting corrosion 
at the modular interface [6-8]. Some have postulated that there is a link between body weight, sports and implant failure, such that some manufactures actually warn of a higher risk of implant failure in patients with BMI greater than $35 \mathrm{~kg} / \mathrm{m}^{2}$. To this date, no bodyweight limitation is mentioned in the FDA approval. In addition, scratching, notching or striking the prosthesis is described to compromise the implant's load-bearing capacity. [9] In literature, no correlation between participation in sports and implant failure has been found. [10,11]

In the literature, modular revision hip arthroplasty failure rate from implant fracture is reported to be $0.30 \%(n=$ $113 / 37,600)$. It occurs most commonly at the modular junction or close to the additional neck segment in $79 \%$ of the cases. Hereby, especially improper use of the implant was described with $0.11 \%$. On the other hand, only one case for primary implant failure was reported. [12]

Purpose of this study was to investigate the occurrence of total hip arthroplasty mechanical failures in a single academic institution not only related to modular implants (1), but also looking at demographics (2), underlying causes (i.e. BMI, sports and fracture pattern) (3), time after initial implantation (4), and implant choice as possible risk factors (5).

\section{Methodology}

A retrospective trial was performed using the arthroplasty database at our academic center. Internal review board approval was obtained. All patients who presented to our outpatient clinic and the emergency department were included between 2011 and 2019. Radiographs and patient charts were searched for mechanical failures of total hip arthroplasty. Information on patients' demographics, comorbidities, year of implant, hip arthroplasty survival, cemented or uncemented implantation, location of failure, mechanism of injury (high versus low energy), other implants used such as plate or cable wires for the treatment of periprosthetic fractures and subsequently revision surgery were all collected. Furthermore, information on the type of implanted arthroplasty was noted.

Hip arthroplasty failures were divided into cup versus femoral shaft. Additionally, the cup was subdivided into inlay versus cup failure, whereas breakage of the femoral shaft was divided into head, neck, shoulder or shaft fractures as illustrated in Fig. 1.

For statistical analysis, Microsoft Excel (Version 16.36) and IBM SPSS version 22 (IBM, Armonk, New York, USA) was used. Demographic data was analyzed for sex, and age in the hip arthroplasty failure groups. Shapiro-Wil testing was applied to identify whether variables were normally distributed. If normality was met, mean and standard error of the mean were calculated. The Pearson correlation coefficient was used to determine the association between the presence of infection, trauma, surgical approach, age at time of initial implantation, time elapsed between initial surgery and implant failure. The correlation coefficient is reported as $r$ (between +1 and -1 ) to measure the strength and direction of a linear relationship. The level of significances was set to $* p$ value $\leq 0.05 ; * * p$ value $\leq 0.01$; and $* * * p$ value $\leq 0.005$.

In total, 13 total hip arthroplasty failures were observed. Female gender comprised of $61.5 \%(n=8 / 13)$ of the THA group. This accounts for $0.9 \%$ of all revision arthroplasties $(0.9 \% ; n=13 / 1421)$ performed during the period of interest. Overall, the mean age of this cohort was $69.08 \pm 11.69$ years at the time of the arthroplasty failure and the mean body mass index was $31.42 \pm 5.29 \mathrm{~kg} / \mathrm{m}^{2}$. Time elapsed between primary implantation and implant failure was $133.85 \pm 103.12$ months.

Arterial hypertension was noted in ten patients and obesity class I (BMI between 30 and $35 \mathrm{~kg} / \mathrm{m}^{2}$ ) in five patients who suffered from THA failure. Other comorbidities include apoplexia, diabetes mellitus, poliomyelitis, myocardial infarction, epilepsy and cardiac insufficiency.

\section{Results}

A structural implant failure was observed in most cases. The implant fractures at the femoral neck (conus) in four patients, at the stem in five cases, and at the inlay in one patient. In this same cohort, there are also two cup failures and one conus dislocation. In one cup failure, the broken cup cage (Zimmer Biomet, Warsaw, IN, USA) grew Cutibacterium acnes. In the other, the broken Alloclassic cup (Zimmer Biomet, Warsaw, IN, USA) grew Cutibacterium acnes and Staphylococcus epidermidis $(r=$ $-0.021 ; p=0.951)$. Two of these failures resulted from a fall at home when moving a heavy object. In the remaining patients, sudden onset of hip pain without any trauma was described ( $r=-0.177 ; p=0.625$ ). Surgical approach chosen for revision was anterolateral (Watson-Jones) in all cases except for one that was posterolateral $(r=$ $-0.065 ; p=0.841)$. In this cohort, no clear underlying causes such as age, physical load or level of activity were identified to result in implant failure. The mean age was $69.08 \pm 11.69$ years $(-0.056 ; p=0.862)$ with a time elapsed between primary implantation and implant failure of $133.85 \pm 103.12$ months $(r=0.179 ; p=0.578)$. All patients denied high level of activity. Although the mean BMI was $31.42 \pm 5.29 \mathrm{~kg} / \mathrm{m}^{2}$ and seven patients were of obesity class I (five patients) or II (two patients), no correlation between the type of implant failure and obesity class was observed $(r=-0.531 ; p=0.186)$.Revision 


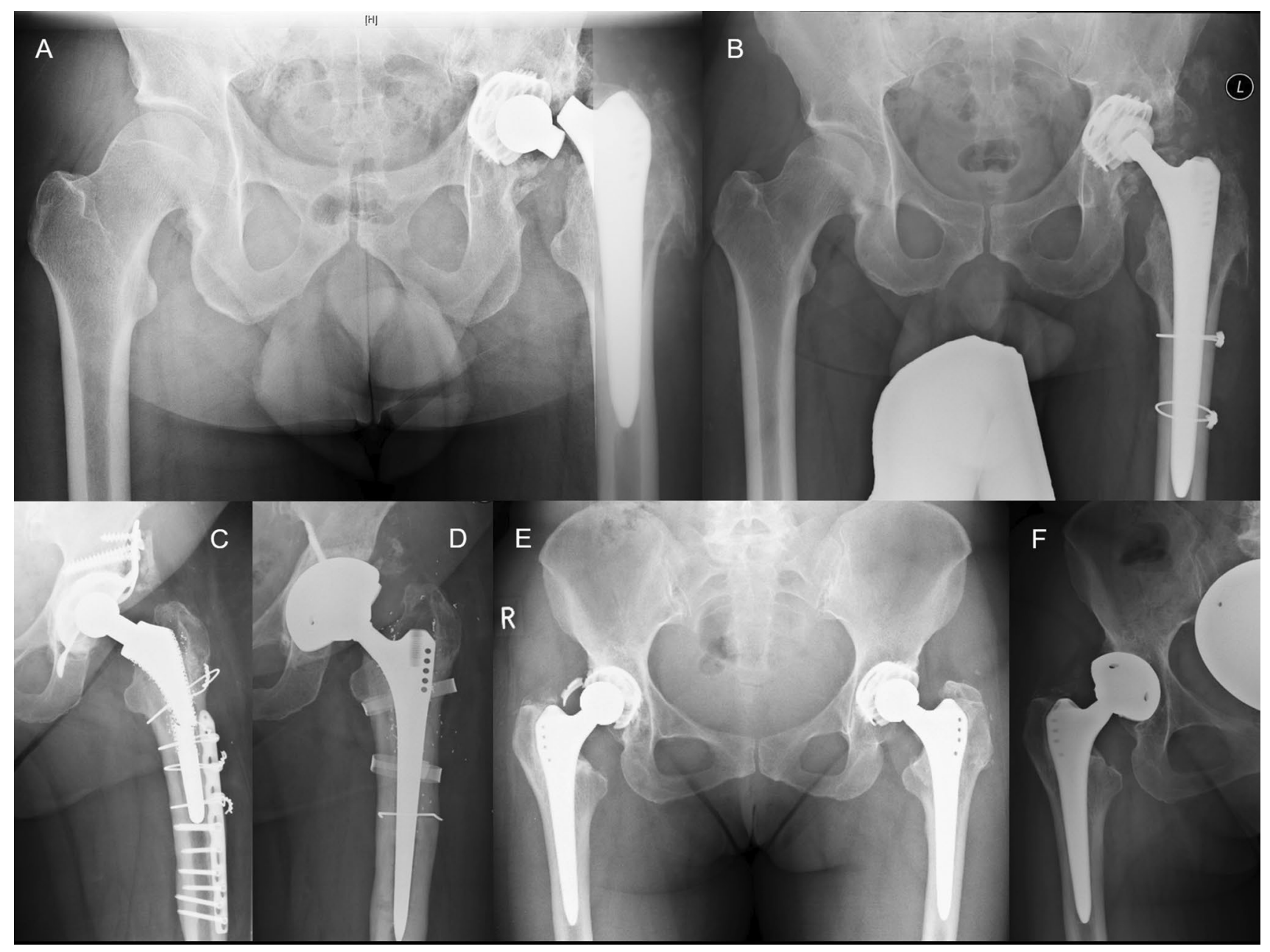

Fig. 1 A Zimmer Alloclassic Zweymüller conus fracture, B after Stem exchange and replacement with a S\&N SLR stem, C broken ESKA stem before and after THA exchange-Modular TMT cup and
Zweymüller Revision stem D, E broken Zimmer Alloclassic cup and after Cup exchange (Zimmer TMT cup, F) surgery was indicated in all patients. Femoral stem and head exchange were performed in three patients. Additionally, inlay exchange in two further cases was required. In one case, a complete reconstruction using a plate and cerclage was performed. In those patients with cup failure, cup and head exchange was performed. For those with hip dislocation, an open reduction was executed and offset increased. In patients with a broken stem, revision focused on bypassing the fracture with a longer stem, supplemented by additional fixation such as cerclage wires as needed. Postoperatively, two complications were identified including one periprosthetic joint infection and the other is periprosthetic fracture. In both cases, further surgeries were required. However, no recurrent implant failure was observed. All cases are illustrated in Table 1.

\section{Discussion}

In total, 13 mechanical failures were found. They affected the stem $(n=5)$, the neck $(n=4)$, followed by the cup $(n=2)$ and inlay. One patient sustained dislocation of the femoral head. No significant correlations between the implant failure and age at time of arthroplasty failure, BMI, physical load, level or energy, time elapsed between primary implantation and implant failure was observed.

Existing literature suggest that inlay is at risk for wear or failure [13]. In Germany, all implant failures are summarized in an annual report to be approximately $2.0 \%$ [14]. This is much higher rate than in our patient cohort at $0.4 \%$ $(n=13 / 3430)$. In this same cohort, we reported 1421 revision arthroplasties at a rate of $0.9 \%(n=13 / 1421)$. [14] Although implant failure is a rare complication, numerous 


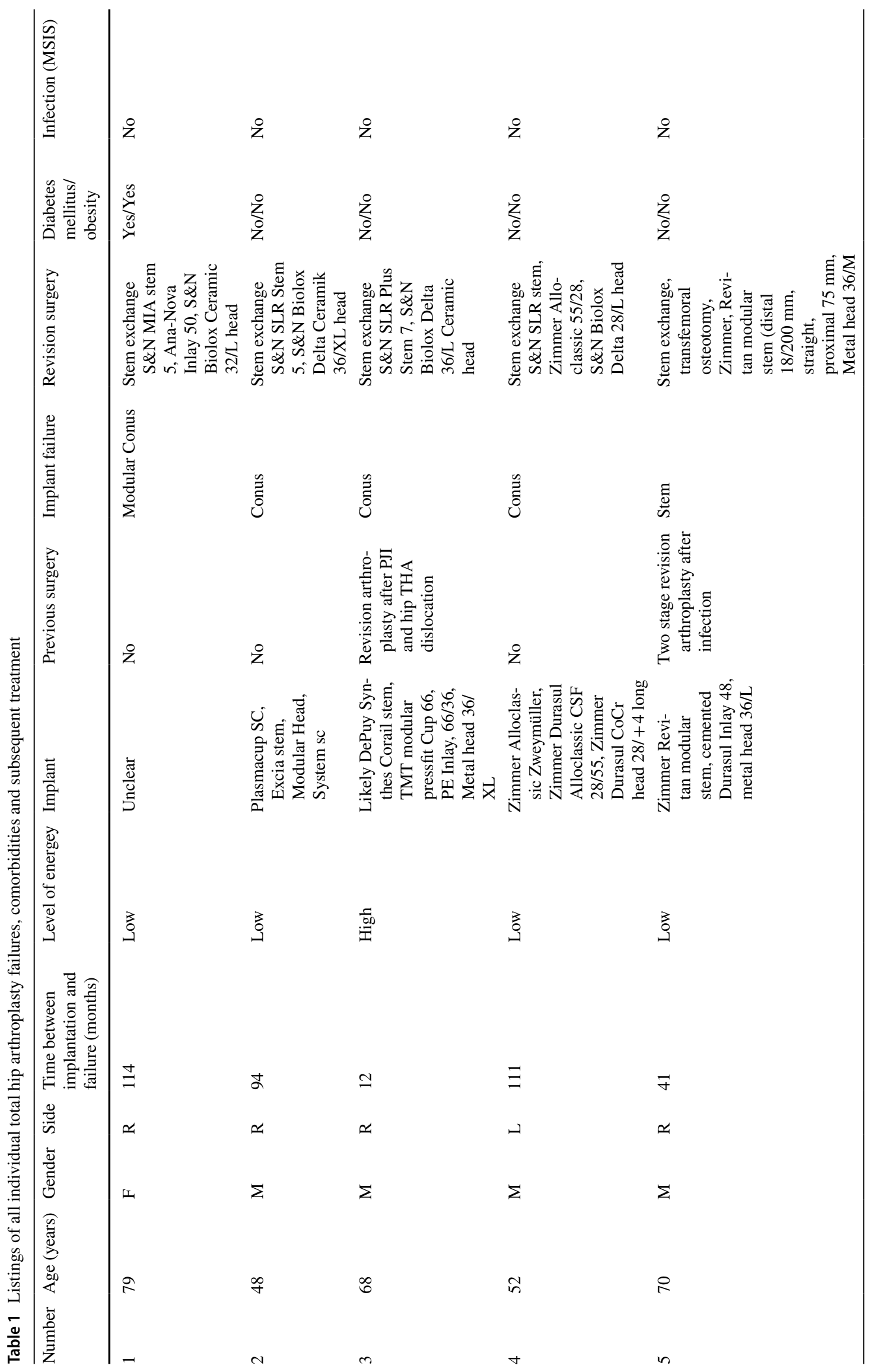




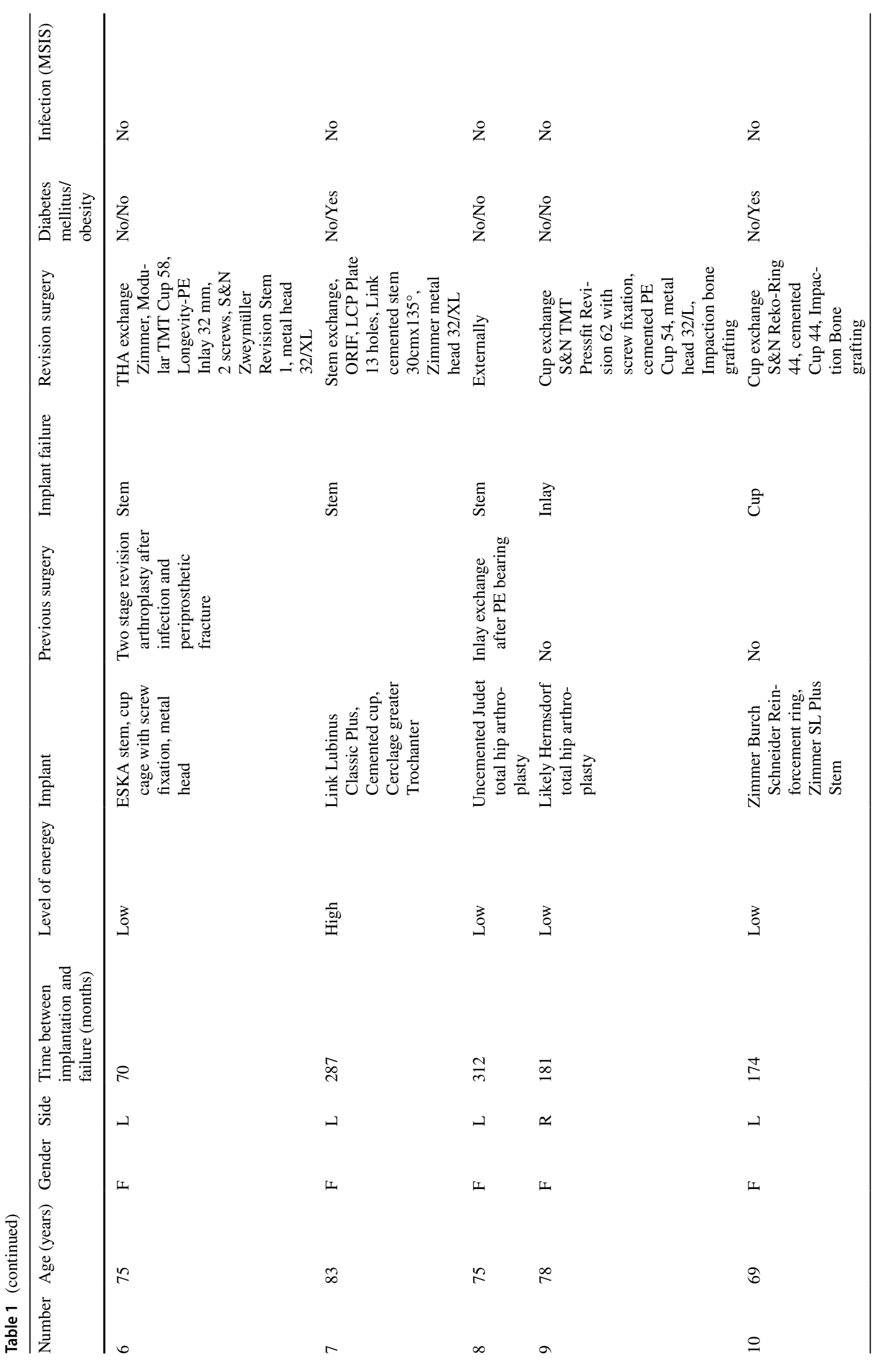




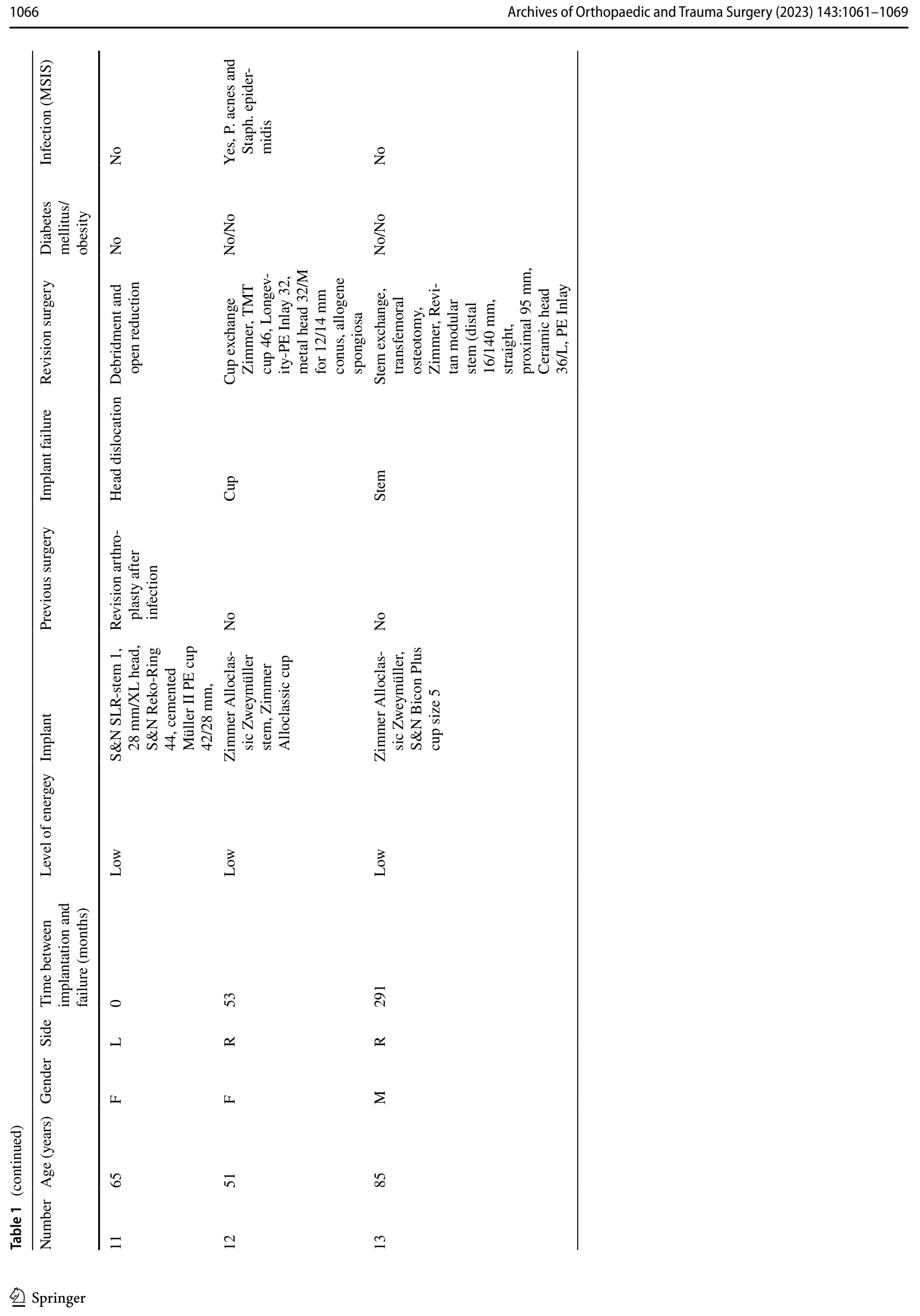


numbers have been reported to the Food and Drug Administration's Manufacturer and User Facility Device Experience Database (MAUDE) [15]. Although not statistically significant, one risk factor for mechanical failure found in our study is obesity. Chee et al. found an increased general complication rate of $22 \%$ for BMI greater than or equal to $30 \mathrm{~kg} / \mathrm{m}^{2}$ as compared to $5 \%$ in patients with BMI less than $30 \mathrm{~kg} / \mathrm{m}^{2}$.[16] Similar findings were found by Haynes et al., who performed a systematic review noting a direct correlation between body mass index and complication rate. [17] In addition, implant manufacturers warn of increased complication rate in obese patients, although there is no strict weight limit [9]. There has been no correlation found between implant failure and sports participation in literature to date $[10,11]$. Another potential risk factors is the usage of high frequency electrocautery, which can cause a change in the structure of the metal in implants and reduce fatigue strength. $[18,19]$

The implants are either made of titanium alloy or cobaltchromium. Latter ones have higher strength, although some reports of mechanical failure have been described. [20, 21] Improvement in material science and implant design have decreased complications rate since total hip arthroplasty was first introduced. To improve the fatigue strength of Ti6AI4V standard alloy, surface treatments like shot peening, deep rolling, ultrasonic shot peening and laser shock peening have been applied [5]. Since the taper is at risk in revision arthroplasty, two-step treatment of cut wire peening and glass bead blasting are especially critical to remove steel contamination. [22] Removal of residual ferrous particles on the surface minimized adverse mechanical and biological reaction. Furthermore, corundum grit and sand blasting are recommend to reduce endurance limit by $35-40 \%$ as compared to polished samples [23, 24]. Of course, overpeening can reduce mechanical strength by softening of the shot peened material [5].

Lateralized neck segment or extra long heads are predisposed to failure in a modular tapered design because of the higher bending moment generated at the modular junction. [15] Additionally, patients with BMI of $\geq 30 \mathrm{~kg} / \mathrm{m}^{2}$ are at risk for revision surgery, which may increase steadily in the upcoming year [12]. To lower the risk, monoblock fluted tapered stems are recommended by some authors even in revision hip arthroplasty. For cup failures, uncoverage of the cup resulting from loss of bone stock such as hips dysplasia can be managed with screw-threaded cups, although this too can concentrates the stress on the implant.

In our cohort, four patients suffered from fractured conus (monoblock tapered prosthesis). In five patients, stem failures were observed, following one broken inlay, two cup failures and one conus dislocation. The mean time between implantation and failure was $133.85 \pm 103.12$ months. Females consisted of $61.5 \%(n=8 / 12)$ of the cohort. One patient suffered from infection with $P$. acnes and $S$. epidermidis $(n=1 / 13 ; 7.7 \%)$, leading to septic loosening and ultimately mechanical failure. In most cases, a sudden atraumatic onset of pain was described but there was a history of falling in two patients. No correlation to physical load like endurance sports was observed. The mean BMI of the cohort was $31.42 \pm 5.29 \mathrm{~kg} / \mathrm{m}^{2}$. As such, most patients in this cohort qualified as obesity class I.

There are several limitations to this retrospective study. First, no comparative control group was included and we only found 13 total hip arthroplasty mechanical failures. Additionally, this is a single academic center study that may have an element of selection bias, since it is routine for our center to accept higher acuity patients from smaller hospitals. Additionally, although all failed implants were reported and sent to the manufacturer, we could not obtain a report as to the cause of failure mechanistically.

\section{Conclusion}

Mechanical failure in total hip arthroplasties is rare and especially affects the stem and neck followed by the cup and inlay. No significant correlations between the implant failure, age, physical load, level of energy, time elapsed between primary implantation and implant failure was observed. Although no significant correlation to BMI was observed most patients qualified as obesity class I. For revision surgery the implant removal-especially the stem when broken-remains challenging and may require an ETO and special instruments for extraction.

\section{Appendix}

\section{Technique for implant exchange}

In patients suffering from stem or conus failure, explanting the remaining stem is difficult. To exclude infection a hip aspiration is recommended and the neocapsule should be sent for microbiological analysis.

In revising THA with conus failures, special extractor and high speed milling machines may be needed. Furthermore, conus failure can be revise with an innovative instrument that contains a $U$ shaped adaptor with two coaxial holes on its jaws. This allows a hole to be drilled in a transverse direction in the proximal part of the remaining prosthesis, such that an adaptor can be attached by a holding pin [16]. Otherwise, the stem needs to be removed in total. Narrow osteotome, electronic bone mill, and stylus touch drill (i.e. Midas Rex, Medtronic, Medtronic, Fort Worth, USA) are all tools to disrupt bone-implant interface to allow for extraction. In implants with coating to promote osteo-integration, 
a transfermoral approach (i.e. Sarcophagus approach developed by Doré) or an extended trochanteric osteotomy (ETO) is suggested to release the prosthesis [17]. Although some authors suggest a controlled back-slap for stem extraction, we do not favor this method.

To repair the cortex cerclages either before or after stem re-implantation with or without strut allograft for augmentation could be considered. The authors suggest the use of a long stem bypassing the osteotomy site by at least two times the diameter of the femur.

For cup exchange an acetabular osteotome system (i.e. Explant Acetabular Cup Removal System, Zimmer Biomet, Warsaw, USA) can be used to expedite extraction for press fit cups. Alternatively, curved mallet or osteotome can be used also. In all cases, inlay and head exchanges are recommended. After surgery, antibiotics should be prescribed until all microbiological results are received. Full weight bearing is indicated in patients who underwent either only cup or short stem exchange. Patients who underwent ETO are recommended to be partial weight bearing.

Funding Open Access funding enabled and organized by Projekt DEAL. No benefits in any form have been received or will be received from a commercial party related directly or indirectly to the subject of this article. No funds were received in support of this study.

\section{Declarations}

Conflict of Interest The authors have no conflict of interest directly related to this work.

Ethical approval IRB approval was obtained.

Informed consent No informed consent was required for this study because of the retrospective design.

Open Access This article is licensed under a Creative Commons Attribution 4.0 International License, which permits use, sharing, adaptation, distribution and reproduction in any medium or format, as long as you give appropriate credit to the original author(s) and the source, provide a link to the Creative Commons licence, and indicate if changes were made. The images or other third party material in this article are included in the article's Creative Commons licence, unless indicated otherwise in a credit line to the material. If material is not included in the article's Creative Commons licence and your intended use is not permitted by statutory regulation or exceeds the permitted use, you will need to obtain permission directly from the copyright holder. To view a copy of this licence, visit http://creativecommons.org/licenses/by/4.0/.

\section{References}

1. Karachalios T, Komnos G, Koutalos A (2018) Total hip arthroplasty: survival and modes of failure. EFORT Open Rev 3(5):232239. https://doi.org/10.1302/2058-5241.3.170068
2. Ulrich SD, Seyler TM, Bennett D, Delanois RE, Saleh KJ, Thongtrangan I, Kuskowski M, Cheng EY, Sharkey PF, Parvizi J, Stiehl JB, Mont MA (2008) Total hip arthroplasties: what are the reasons for revision? Int Orthop 32(5):597-604. https://doi.org/ 10.1007/s00264-007-0364-3

3. Sul YT, Johansson CB, Petronis S, Krozer A, Jeong Y, Wennerberg A, Albrektsson T (2002) Characteristics of the surface oxides on turned and electrochemically oxidized pure titanium implants up to dielectric breakdown: the oxide thickness, micropore configurations, surface roughness, crystal structure and chemical composition. Biomaterials 23(2):491-501. https://doi.org/10. 1016/s0142-9612(01)00131-4

4. Bergmann G, Graichen F, Rohlmann A (2004) Hip joint contact forces during stumbling. Langenbecks Arch Surg 389(1):53-59. https://doi.org/10.1007/s00423-003-0434-y

5. Sonntag R, Reinders J, Gibmeier J, Kretzer JP (2015) Fatigue performance of medical Ti6Al4V alloy after mechanical surface treatments. PLoS ONE 10(3):e0121963. https://doi.org/10.1371/ journal.pone. 0121963

6. Sivash KM (1969) The development of a total metal prosthesis for the hip joint from a partial joint replacement. Reconstr Surg Traumatol 11:53-62

7. Grupp TM, Weik T, Bloemer W, Knaebel HP (2010) Modular titanium alloy neck adapter failures in hip replacement-failure mode analysis and influence of implant material. BMC Musculoskelet Disord 11:3. https://doi.org/10.1186/1471-2474-11-3

8. Wilson DA, Dunbar MJ, Amirault JD, Farhat Z (2010) Early failure of a modular femoral neck total hip arthroplasty component: a case report. J Bone Joint Surg Am 92(6):1514-1517. https://doi. org/10.2106/JBJS.I.01107

9. Zimmer (2014) Avenir müller stem. D011500294 EN 02/14. Zimmer GmbH, Winterthur

10. Jassim SS, Douglas SL, Haddad FS (2014) Athletic activity after lower limb arthroplasty: a systematic review of current evidence. Bone Joint J 96-B(7):923-927. https://doi.org/10.1302/0301620X.96B7.31585

11. Meek RMD, Treacy R, Manktelow A, Timperley JA, Haddad FS (2020) Sport after total hip arthroplasty: undoubted progress but still some unknowns. Bone Joint J 102(6):661-663. https://doi. org/10.1302/0301-620X.102B6.BJJ-2020-0208

12. Krueger DR, Guenther KP, Deml MC, Perka C (2020) Mechanical failure of 113 uncemented modular revision femoral components. Bone Joint J 102(5):573-579. https://doi.org/10.1302/0301-620X. 102B5.BJJ-2019-1333.R2

13. IL: American Academy of Orthopaedic Surgeons (AAOS) (2020) 2020 Annual Report.

14. Jansson V (2020) Endoprothesenregister Deutschland (EPRD) Jahresbericht 2020 Mit SIcherheit mehr Qualität. EPRD

15. Skendzel JG, Blaha JD, Urquhart AG (2011) Total hip arthroplasty modular neck failure. J Arthroplasty 26(2):338-344. https://doi. org/10.1016/j.arth.2010.03.011

16. Chee YH, Teoh KH, Sabnis BM, Ballantyne JA, Brenkel IJ (2010) Total hip replacement in morbidly obese patients with osteoarthritis: results of a prospectively matched study. J Bone Joint Surg Br 92(8):1066-1071. https://doi.org/10.1302/0301-620X.92B8. 22764

17. Haynes J, Nam D, Barrack RL (2017) Obesity in total hip arthroplasty: does it make a difference? Bone Joint J 99-B(1 Supple A):31-36. https://doi.org/10.1302/0301-620X.99B1.BJJ-20160346.R1

18. Huber G, Weik T, Morlock MM (2009) Damage to a hip endoprosthesis caused by high-frequency electrocautery. Orthopade 38(7):622-625. https://doi.org/10.1007/s00132-009-1442-6

19. Sonntag R, Gibmeier J, Pulvermacher S, Mueller U, Eckert J, Braun S, Reichkendler M, Kretzer JP (2019) Electrocautery damage can reduce implant fatigue strength: cases and in vitro 
investigation. J Bone Joint Surg Am 101(10):868-878. https:// doi.org/10.2106/JBJS.18.00259

20. Fink B, Urbansky K, Schuster P (2014) Mid term results with the curved modular tapered, fluted titanium Revitan stem in revision hip replacement. Bone Joint J 96-B(7):889-895. https://doi.org/ 10.1302/0301-620X.96B7.33280

21. Nasr PJ, Keene GS (2015) Revision of a fractured uncemented revision stem using a custom designed punch and retrograde through-knee approach. Case Rep Orthop 2015:485729. https:// doi.org/10.1155/2015/485729

22. Schuh A, Uter W, Kachler W, Goske J, Zeiler G, Lill C (2005) Comparative surface examinations on corund blasted titanium implants and explants in total hip arthroplasty. Arch Orthop Trauma Surg 125(10):676-682. https://doi.org/10.1007/ s00402-005-0050-0
23. Leinenbach C, Eifler D (2006) Fatigue and cyclic deformation behaviour of surface-modified titanium alloys in simulated physiological media. Biomaterials 27(8):1200-1208. https://doi.org/10. 1016/j.biomaterials.2005.08.012

24. Baleani M, Viceconti M, Toni A (2000) The effect of sandblasting treatment on endurance properties of titanium alloy hip prostheses. Artif Organs 24(4):296-299. https://doi.org/10.1046/j.15251594.2000.06486.x

Publisher's Note Springer Nature remains neutral with regard to jurisdictional claims in published maps and institutional affiliations. 